\title{
Aplicación De Los Métodos Científicos De Examen En La Investigación De Pinturas. La Pequeña Madonna De Foligno De Rafael
}

Luis Rodrigo Rodríguez-Simón

Doctor en Bellas Artes. Departamento de Pintura y Restauración. Facultad de Bellas Artes. Universidad de Granada, Granada, España

Miguel Ángel León-Coloma

Doctor en Historia del Arte. Departamento de Patrimonio Histórico. Facultad de Humanidades, Universidad de Jaén, Jaén, España

Vicente del Sol López.

Professor. Departamento de Lenguajes y Sistemas Informáticos. Universidad de Granada, Granada, España

Doi: 10.19044/esj.2018.v14n3p494 URL:http://dx.doi.org/10.19044/esj.2018.v14n3p494

\begin{abstract}
The aim of this article is to highlight the importance of Scientific Methods of Examination for the authentication of works of art and, where applicable, attribution to a specific period, school or artist. The results obtained from the technologies applied may provide particularly important data for cataloguing the works in question. Furthermore, they may be compared, in terms of technique and aesthetics, with other similar documents, acquired from paintings of the same author, period or style already identified through historical works. The use of these wide-ranging sets of instruments have been tested on a version of The Madonna of Foligno by Raphael, and very important information on the creative process as well as other highly significant technical data have been gathered to attribute this work to the painter from Urbino.
\end{abstract}

Keywords: Radiography, infrared reflectography, stratigraphy, authentication, attribution, Litle Madonna of Foligno, Raphael

\section{Resumen}

El propósito de este artículo es evidenciar la importancia de la correcta interpretación de los resultados obtenidos a partir de los métodos científicos de examen para la autentificación de las obras de Arte y, en su caso, la atribución a un periodo, a una escuela o a un artista concreto. Los resultados obtenidos a partir de las tecnologías aplicadas pueden llegar a proporcionar datos de especial relevancia para la catalogación de las obras en cuestión. 
Además, podrán ser comparados, técnica y estéticamente, con otros documentos similares de pinturas del mismo autor, cronología o estilo, ya reconocidas por la historiografía. La utilización de estos equipos instrumentales de gran alcance se han ensayado sobre lo que estimamos como una versión de La Madonna de Foligno de Rafael Sanzio, obteniéndose información muy importante sobre su proceso de gestación y otros datos técnicos de gran transcendencia para la atribución de esta obra al pintor de Urbino.

Palabras clave: Métodos científicos, autentificación, atribución, Pequeña Madonna de Foligno, Rafael Sanzio

\section{Introduction}

La Pequeña Madonna de Foligno, objeto de nuestro estudio [Imagen $\mathrm{n}^{\mathrm{o}}$ 1] ha sido considerada desde hace años como una simple copia del siglo XIX, si bien nuestros estudios nos llevaron a valorarla en un principio como una reproducción de época, realizada por algún discípulo o seguidor de Rafael. Por esta razón, se decidió abordar un estudio más profundo basado en metodologías científicas con el propósito de conocer la materialidad de la pintura y su estructuración interna, su proceso creativo y la naturaleza y disposición de los materiales pictóricos empleados, así como las intervenciones de restauración llevadas a cabo en siglos posteriores. Todo ello con la finalidad de despejar las dudas sobre su cronología.

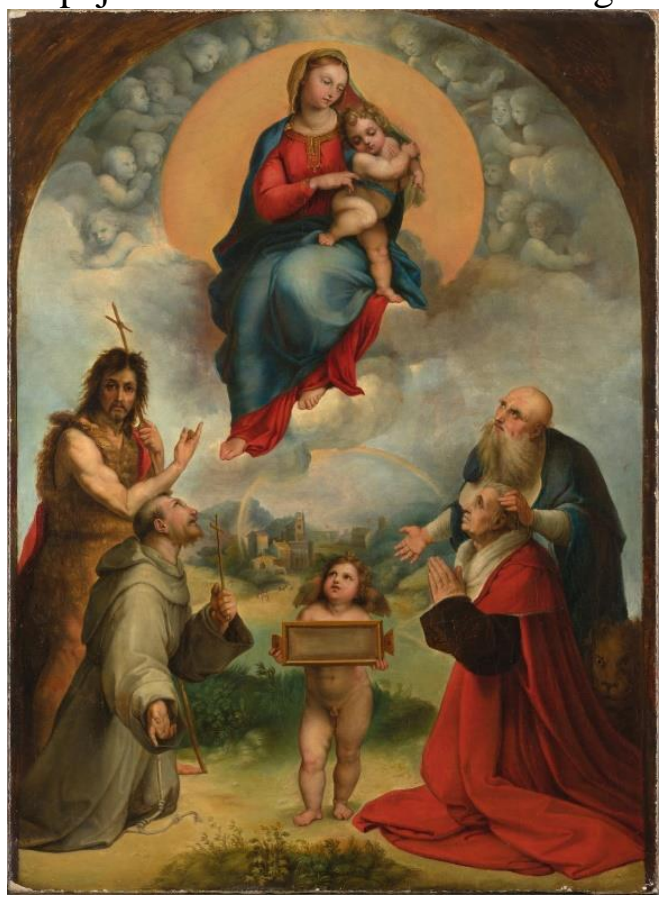

Imagen $\mathbf{n}^{0} \mathbf{1}$ 
El estudio que aquí presentamos resume los resultados obtenidos del conjunto de exámenes de superficie y métodos de análisis utilizados para abordar la investigación sobre La Pequeña Madonna de Foligno, empleando las técnicas que se especifican en el apartado 3. Metodología. Materiales y Métodos Científicos de Examen, con la finalidad de determinar aquellos recursos pictóricos, que pudieran estar presentes en nuestra obra, así como los materiales artísticos utilizados.

Sin embargo, la interpretación de los datos adquiridos y los estudios comparativos, a nivel técnico y artístico, con otras obras del pintor de Urbino han proporcionado información de especial relevancia para plantear su atribución a Rafael Sanzio, con la relativización de su propia intervención personal, característica de su producción romana que, desbordante en encargos, solo pudo hacer frente con la asistencia de un taller que contaba con destacados colaboradores.

La pintura que estudiamos $(93,50 \times 66,50 \mathrm{~cm})$ reproduce una escena idéntica a la que exhibe la original y conocida Madonna de Foligno de los Museos Vaticanos (320 x $194 \mathrm{~cm}$ ), representando a la Virgen con el Niño en un plano celestial y a san Juan Bautista, san Francisco de Asís, san Jerónimo, Segismundo de Conti (que fue protonotario y camarlengo de Julio II) y un putto con una cartela en un plano terrenal [Imagen $\mathrm{n}^{\circ} 1$ ].

La existencia de numerosas diferencias entre las dos obras obliga a rechazar la hipótesis de que se tratara de una copia, pues si así fuera el copista hubiera reproducido en la Pequeña Madonna de Foligno los detalles existentes en la versión del Vaticano, como por ejemplo las decoraciones del brocado del cuello y de la bocamanga de la túnica de la Virgen o la del pañuelo que cubre su cabeza, entre otras.

Por otra parte, los resultados de los estudios técnicos ponen de manifiesto su calidad pictórica, como es posible apreciar con reflectografía infrarroja; cualidad confirmada, además, por su compleja estructuración estratigráfica a nivel interno, así como por la utilización, mezclas y distribución de los pigmentos empleados para conseguir el resultado final.

Pero además existen fragmentos de gran perfección, como el putto, las figuras de San Juan Bautista y San Francisco, la cabeza de San Jerónimo o la dogalina de Segismundo de Conti, entre otros. Por otra parte, la calidad original de otros fragmentos, como el rostro de la Virgen resulta degradada por la presencia de repintes; en otros aspectos tenemos que volver a invocar la relativización de la intervención personal de Rafael.

\section{Estudio histórico-artístico}

La pintura que estudiamos [Imagen $\mathrm{n}^{\mathrm{o}} 1$ 1] reproduce fidelísimamente la composición de la Madonna de Foligno (Pinacoteca Vaticana), encargo del humanista Sigismondo de' Conti, canciller de Foligno, scriptor apostolicus y 
secretario de Julio II, que aparece retratado con agudo realismo, a partir quizá de la máscara fúnebre (Jones, Penny, 1983: 89 y Nesselrath, 2013: 59), presentado a la Madonna por san Jerónimo que, habiendo detentado también el cargo de secretario pontificio, actúa como su patrón. Frente a ellos un agreste y espiritualizado san Juan Bautista y un extático san Francisco, patrono este de la orden que regía la basílica romana de Santa Maria in Aracoeli a la que Conti, fallecido en febrero de 1512, destinó la pala como memoria fúnebre de su propia sepultura. Un encargo de especial trascendencia para el pintor de Urbino ya que le permitía abordar un gran cuadro de altar accesible al público romano con el que publicitar su prestigio más allá de los palacios vaticanos (Meyer zur Capellen, 2006: 73).

La composición, reveladora de la incesante búsqueda de nuevas soluciones que caracterizó su trayectoria artística, supone una modificación de la relación espacial y espiritual de los personajes respecto de sacre conversazioni anteriores (pale Colonna, Ansidei y Virgen del baldaquino), remitiendo la Madonna con el Niño al plano celestial y haciéndolos capitalizar todas las miradas de los personajes, salvo la del Bautista que como Precursor y último de los profetas se dirige al espectador anunciando $-\mathrm{y}$ señalando- al Salvador del mundo. Tal replanteamiento permite abrir en el centro de la composición un evanescente paisaje, presuntamente de la ciudad de Foligno, pletórico de sugestiones véneto-ferraresas, donde se narra el milagroso suceso que originó seguramente el encargo de la obra: la caída de un meteorito o más bien el proyectil disparado por una bombarda (Violini, 2013: 84) que no habría causado daño alguno en la casa de Conti. Un cuadro votivo por tanto, fechable ca. 1511-12, cuando Rafael y su equipo pintan en la Stanza de Eliodoro temas que, como este, ilustran la protección divina sobre la Iglesia y sus representantes.

La Virgen presenta la cabeza cubierta con una rica tela rayada, como la Madonna Aldobrandini y la posterior Virgen de la Silla. La displicente manera con la que sujeta al Niño por la cintura, apenas con un dedo, redunda en una solución ya presente en la Virgen de la Palma, realización florentina del artista, valorada como primer estudio de la Madonna de Foligno (Ferino Pagden y Zancan, 1992: 104). El dibujo preparatorio del cuadro que afecta al grupo principal (London: British Museum) es bastante fiel respecto de la obra final salvo por la postura de las piernas del Niño que, desbordando la silueta de la madre, redefine la geométrica estructura romboidal en la que se funden las dos figuras. La contorsionada pose de aquel, contrapuesta a la de la Virgen, parece una variación de las Madonne Bridgewater y de la coetánea Alba, derivando en último término del Tondo Doni de Miguel Ángel (Bonis, 2013: 151). El planteamiento rotatorio de las dos figuras, fusionadas en una elegante serpentinata, resulta decisivo para superar el tradicional estatismo de la imagen sacra y su carácter contemplativo, sometiéndola a un movimiento que 
la dramatiza, convirtiéndola así en representación histórica, genero definido por Alberti (De la pintura II, 35) que afectaba no tanto al tema como a su definición formal (Coliva, 2006: 49-50). Una aureola solar envuelve a la Virgen (amicta sole) como al Cristo juez (Sol Iustitia) y al Espíritu Santo de la Disputa del Sacramento, donde también aparecen los evanescentes querubines pictóricamente disueltos en nubes de grisalla.

El esquema piramidal de la composición, sólidamente trabado mediante la simétrica arquitectura que definen las figuras (Giorello, 2013: 53), crea armónicos y dinámicos vínculos entre los personajes, estableciendo asimismo correspondencias entre cielo y tierra. La enfática gestualidad de aquellos, propia de la pintura de estos años romanos, establece precisas relaciones entre el plano figurativo y el espacio real, al tiempo que jerarquiza a los actores de este drama sacro. El brazo extendido de san Francisco, que tiene su contrapunto en el de san Jerónimo, introduce al espectador en la escena, mientras que el de este reconduce la mirada hacia el paisaje umbro del milagro. Las rígidas manos orantes del comitente, como el gesto indicativo del Bautista, subrayan la epifanía celeste a la que también dirige su mirada el delicioso angelote reggitarga, otro motivo que Rafael recupera de su producción florentina, concretamente los que flanquean la alegoría de la $\mathrm{Fe}$ en una de las predelas del Descendimiento Borghese, si bien con un mayor compromiso clasicista a través del desnudo y la tabula ansata que sin inscripción alguna sujeta. Vasari ponderaría esta figura como exponente de la gracia rafaelesca: "che di belleza di volto e di corrispondenza della persona non si può fare nè più grazioso, nè meglio" (Vasari, 1992: II, 37).

A diferencia de la Madonna Sixtina, la de Foligno no fue realizada a partir de un cartón, sino trazando el dibujo sobre la imprimación con una punta metálica (Neselrath, 2013: 67; Santamaria y Morresi, 2013: 99), lo que permite presuponer la existencia de un modelo previo.

La Pequeña Madonna de Foligno, objeto de este estudio, muestra una estrechísima relación con la gran pala vaticana, no obstante la constatación de diferencias, algunas de las cuales pueden inducir a remitirla a un estadio previo. Así el cromatismo más amortiguado, con una tonalidad amarillo verdosa dominante, más propia de su producción florentina, en la que el costoso lapislázuli que singulariza la tonalidad dominante de la pala ha sido aquí deliberadamente diluido con cobalto. También el espacio figurativo resulta algo más ancho en la versión pequeña permitiendo, entre otras cosas, tener una visión más completa del león jeronimiano. En contrapartida, la aureola de nebulosos querubines que envuelve a la Madonna aparece cortada. El detallismo se extrema en el gran cuadro de altar en detrimento del lienzo pequeño en el que el velo de la Virgen carece de la decoración rayada, la cenefa de su escote resulta más estrecha y menos recamada de bordado o la barba del san Francisco menos poblada. Otras diferencias afectan a la anatomía y, sobre 
todo, a la estructura y posición de las cabezas: En la Pequeña Madonna de Foligno los rostros de la Virgen y el Niño son más amplios, más redondos; el antebrazo del Bautista resulta más grueso, su cabeza algo menos inclinada y sus ojos más grandes y de mirada más intensa. La estructura del cráneo de san Francisco es más alargada y el perfil de su rostro evidencia un dibujo irregular. La cabeza de san Jerónimo está planteada con menos volumen y rasgos más afilados, mientras que la del comitente resulta más pequeña y su rostro no tan demacrado. La cabeza del putto que sostiene la cartela, de espléndida factura, resulta algo más pequeña y su escorzo más atenuado. Por último, la arquitectura del paisaje está planteada con menos detalle y proporciones más estrechas.

\section{Metodología. Materiales y Métodos Científicos de Examen}

Para llevar a cabo esta investigación se han utilizado los siguientes métodos de examen: radiografía y reflectografía infrarroja. También técnicas microscópicas, como microscopía óptica con iluminación visible y ultravioleta y microscopía electrónica de barrido con microanálisis por energía dispersiva de rayos $\mathrm{X}$. Y técnicas analíticas como cromatografía de gases-espectrometría de masas. (Matteini, M., Moles, A., 2001; Prous, S. 2008; Del Egido, M. y Juanes, D. 2010; Pinna, D., Galeotti, M., Mazzeo, R., 2010; Garrido Pérez, C., 1985)

La radiografía se ha realizado con un equipo de rayos $\mathrm{X}$ modelo Baltospot Art-X-110/DA/0 \& HAND X, con Cabezal Portátil direccional de Potencial Constante refrigerado por aire con tubo Metal-Cerámico; Kilovoltaje y miliamperaje $110 \mathrm{kV}-5,4 \mathrm{~mA}$; foco 0,4 x 0,4 limitado a 90kV. Los documentos radiográficos permiten el conocimiento en profundidad de las pinturas proporcionando imágenes de la configuración interna de los soportes y de las diferentes capas pictóricas constituyentes y ponen de manifiesto la técnica del artista, el tipo de pincelada, la forma de aplicación de las preparaciones y de los distintos colores, la disposición de los pigmentos, los cambios de composición introducidos por el propio artista durante la realización de la pintura, así como las superposiciones y modificaciones introducidas en épocas posteriores.

La reflectografía infrarroja se ha llevado a cabo con el prototipo diseñado y puesto a punto por Duilio Bertani ${ }^{2}$, con una matriz CCD o revelador InGaAs de 252x316 pixels, que tiene una penetración de $1600 \mathrm{~nm}$ y consta de un objetivo Schneider APO-SYMMAR-L 300/5,6.

\footnotetext{
${ }^{2}$ Deseamos expresar nuestro agradecimiento a Dña Carmen Pérez, y a D. Juan Pérez Miralles, que han permitido y llevado a cabo, respectivamente, las tomas reflectográficas de esta pintura con el prototipo diseñado por el Dr. Duilio Bertani, al que también manifestamos nuestra más sincera gratitud.
} 
Los principales resultados que se pueden obtener mediante esta técnica son: la visualización de los diseños preliminares o dibujos subyacentes cuando hayan sido realizados con materiales que puedan ser capturados por el infrarrojo, como es el caso del color negro; los cambios de composición e iconografía que se producen entre el proyecto preliminar y la pintura definitiva; las rectificaciones de los diseños introducidas por el artista en las capas pictóricas intermedias durante el proceso de gestación de las pinturas; el examen de firmas e inscripciones tapadas, superpuestas o raspadas, etc. Y la diferenciación de las características particulares del diseño de cada escuela y/o pintor, (Finaldi, G., Garrido, C., 2006; Ibáñez Barberán, G., 2010).

Las técnicas microscópicas y analíticas han sido aplicadas a partir de minúsculas micromuestras extraídas de la superficie pictórica; el microanálisis de pigmentos se ha llevado a cabo con las estratigrafías preparadas a partir de las mismas; la identificación de aglutinantes se ha realizado con microscópicas partículas obtenidas de las capas de color.

Microscopía óptica utilizada para la observación de las estratigrafías o secciones transversales de la pintura. El examen preliminar de estas muestras pictóricas ha sido realizado, por una parte, con un microscopio óptico de luz polarizada, con nícoles paralelos y cruzados (Carl Zeiss, modelo Jenapol U); y por otra con un microscopio de Iluminación Ultravioleta (Olympus, modelo CX41RF).

La información aportada por microscopía óptica es esencial para reconocer la microestructura interna derivada del proceso creativo seguido por el pintor, de vital importancia en la autentificación de la obra. Asimismo permite la visualización de la imagen microscópica con la secuencia de estratos y los colores reales de los pigmentos constituyentes de cada una de las capas, su distribución, molturación y textura.

Con microiluminación ultravioleta se consigue distinguir mejor la estructuración estratigráfica interna debido a la fluorescencia que emiten tanto pigmentos como aglutinantes.

Microscopía Electrónica de Barrido (SEM) con microanálisis elemental (EDX), aplicada sobre las estratigrafías preparadas a partir de las referidas micropartículas.

Instrumentación: Microscopio electrónico de barrido SEM Leo 1430VP, asociado a un sistema de microanálisis elemental por energía dispersiva de rayos X, Inca 350, versión 17, (en adelante SEM-EDX). La microscopía electrónica de barrido permite la identificación de elementos con número atómico bajo, incluido el carbono. La obtención de imágenes de electrones retrodispersados (BSE) muestra el $\mathrm{n}^{\mathrm{o}}$ atómico medio de los pigmentos, y las imágenes de electrones secundarios (SE) proporcionan información sobre la textura y estructura; mientras que el análisis elemental de los pigmentos se obtiene por espectroscopia dispersiva de rayos X (EDX). Las 
imágenes de SE y BSE y los análisis por energía dispersiva de rayos X fueron adquiridos a $20 \mathrm{Kv}$ de aceleración. Los espectros se adquieren durante 50 segundos, con una resolución de 20 ev/Ch y una tasa de adquisición de aprox. 3000cps.

Esta técnica instrumental se aplica para la localización, distribución porcentaje, tamaño de granos e identificación estricta de los pigmentos y materiales de carga que constituyen los distintos estratos internos, desde la preparación hasta las capas pictóricas más superficiales como las veladuras.

Cromatografía de Gases-Espectrometría de Masas, aplicada sobre minúsculas partículas extraídas de la superficie de la pintura. Las muestras se han tratado para su separación y análisis en cromatografía con el reactivo de metilación Meth-prep II para la detección de las sustancias oleo-resinosas y ceras. Para los hidratos de Carbono y las proteínas se lleva a cabo una hidrólisis y posterior derivatización mediante sililación con TBDMSTFA en piridina.

Sirve para reconocer mezclas de compuestos, generalmente materiales orgánicos, volátiles o transformables en derivados volátiles. Mediante esta técnica se pueden identificar aceites, resinas, ceras y gomas, facilitando la caracterización de los materiales ligantes que dan cohesión a los pigmentos, lo que permite la determinación de la técnica pictórica.

\section{Resultados y Discusión}

Este trabajo tiene su argumentación en la utilización de los exámenes científicos con la finalidad de complementar la investigación en la Historia del Arte (Prous, S. 2008; Del Egido, M. y Juanes, D. 2010; Pinna, Galeotti, Mazzeo, 2010) y, en particular, su aplicación en pinturas de especial relevancia artística, como el caso que nos ocupa. Para ello, por una parte nos hemos basado en la interpretación de los documentos obtenidos de cada una de las técnicas aplicadas, y por otra, se ha realizado un estudio comparativo de sus resultados con otros similares pertenecientes a otras pinturas de Rafael y también con trabajos publicados por otros especialistas sobre originales del pintor de Urbino.

\section{Radiografía}

Los documentos radiográficos muestran una falta de claridad debido a la opacidad de las capas subyacentes, elaboradas con una gran cantidad de blanco de plomo, que por su alta absorción enmascara la lectura proporcionada por los distintos pigmentos [Imagen $\mathrm{n}^{\mathbf{0}} 2$ ]. 


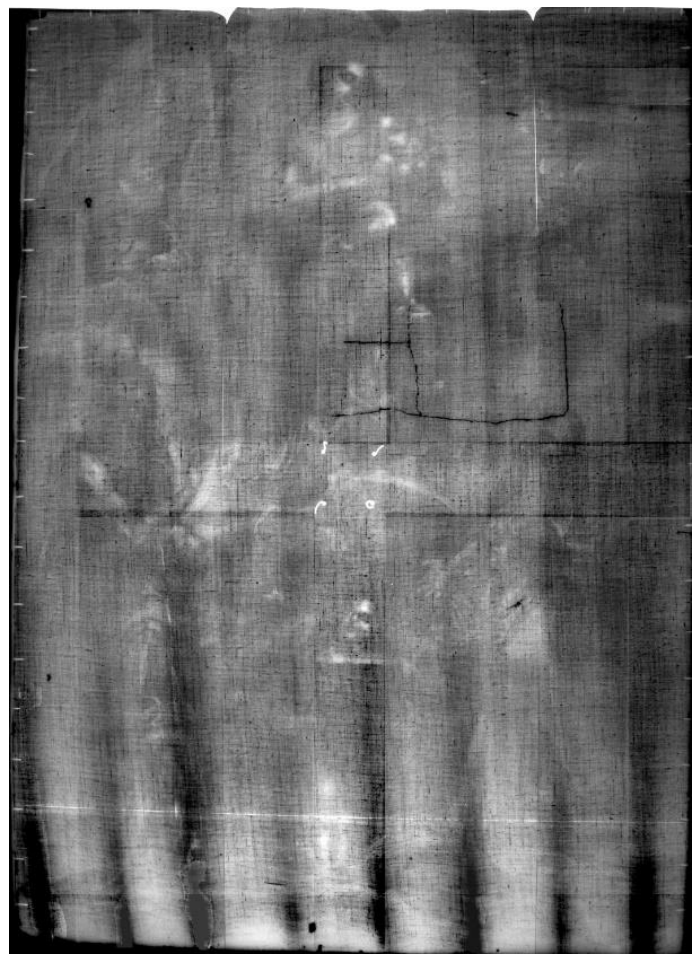

Imagen $\mathbf{n}^{0} 2$

Estas capas internas de albayalde pertenecen, por una parte, a la imprimación original oleosa, aplicada por el pintor sobre la preparación primigenia de gesso. Y por otra, al enlucido de blanco de plomo añadido en las transposiciones de soporte; proceso realizado en nuestra obra. Esta imprimación ha sido detectada en las observaciones estratigráficas, por lo que pensamos que no llego a eliminarse en el proceso de transposición de tabla a lienzo realizado en el siglo XIX en Francia, debido a la preocupación de los restauradores franceses por la conservación de los dibujos subyacentes originales, tal como se describe en los documentos de la época. Sin embargo, las capas de yeso originales eran eliminadas junto a los soportes de madera en los procesos de transposición de tabla a tela.

Estos estratos de plomo hacen que la mayoría de las pinturas que han sufrido este cambio sean opacas a los rayos X, lo que impide la obtención de radiografías con la suficiente nitidez para facilitar su interpretación (González y Alonso 2011: 104; Mottin et al. 2012: 351).

En general, las pinturas de Rafael manifiestan contrastes radiográficos muy acusados, como consecuencia de sus propias características técnicas, por ejemplo cuando presentan el modelado de rostros, manos y partes desnudas de las figuras ejecutado con golpes de luz de pintura densa y blanco de plomo, como es el caso del retrato de Doña Isabel de Requesens, en la que el estudio radiográfico de las carnaciones revela una opacidad mayor y un modelado más 
trabajado en el rostro, cuello y escote (Mottin et al. 2012: 360). También este proceder puede ser detectado en las radiografías de las obras que han sufrido la sustitución de su primer soporte lígneo, en las que destacan las siluetas de las figuras y las áreas iluminadas de las carnaciones al estar modeladas con albayalde y densidad de pasta, lo que ocasiona que estas zonas no sean encubiertas totalmente por la absorción de las capas subyacentes de blanco de plomo procedentes de las transposición, como ocurre en el caso de La pequeña Madonna de Foligno [Imagen $\mathrm{n}^{\mathbf{0}}$ 3].

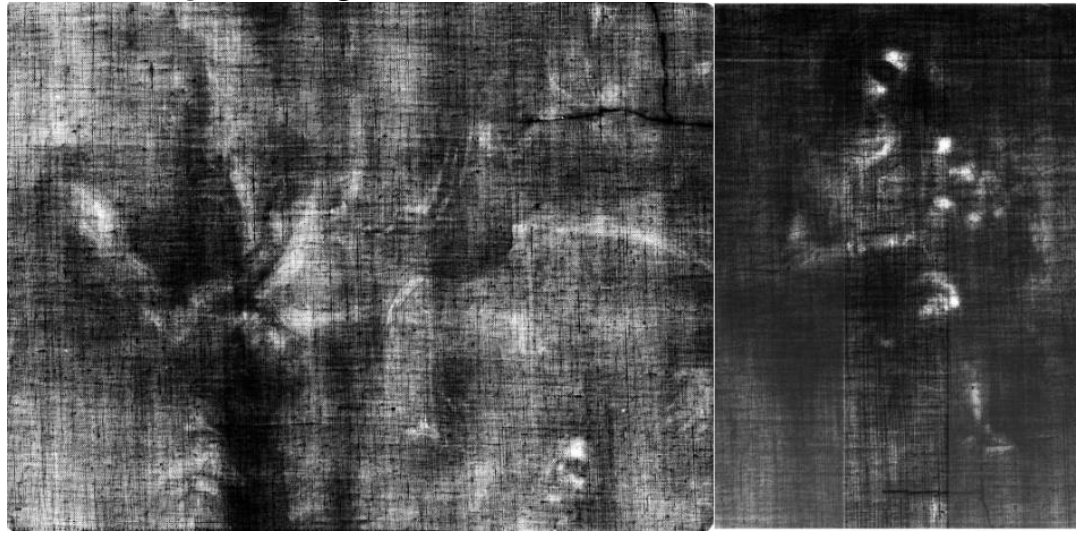

Imagen $n^{\circ} 3$

Debido a esta radiopacidad no resulta posible detectar el alcance de las intervenciones restauradoras.

\section{Reflectografía Infrarroja}

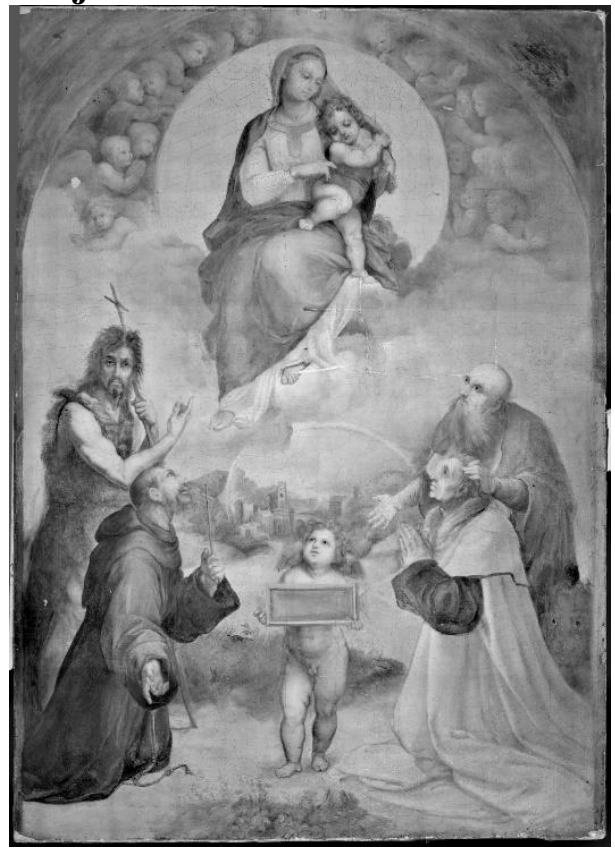

Imagen $n^{\circ} 4$ 
Las conclusiones extraídas a partir de la interpretación de la imagen capturada con reflectografía infrarroja [Imagen $\mathrm{n}^{\circ} 4$ ] han sido determinantes para la atribución de la pintura, por la información proporcionada y por su importancia al acercarnos al proceso creativo de la misma, permitiendo asimismo la comparación y la aproximación de nuestros resultados con otros similares existentes, a nivel subyacente, en otras obras autógrafas de Rafael estudiadas con esta misma técnica, posibilitándonos constatar la existencia de muchas similitudes.

Con la radiación infrarroja se han podido apreciar un conjunto de trazos realizados con piedra negra o lápiz negro, a juzgar por las características de los mismos, que definen un dibujo nítido, de trazo fino y tipo silueteado, ajustado a los contornos de figuras y vestimentas y a las arquitecturas de la villa de Foligno, algunos realizados sobre la imprimación y otros sobre las capas intermedias de pintura, ejecutados durante la distintas fases de la creación pictórica. [Imagen $\mathrm{n}^{\circ} 5$ ].

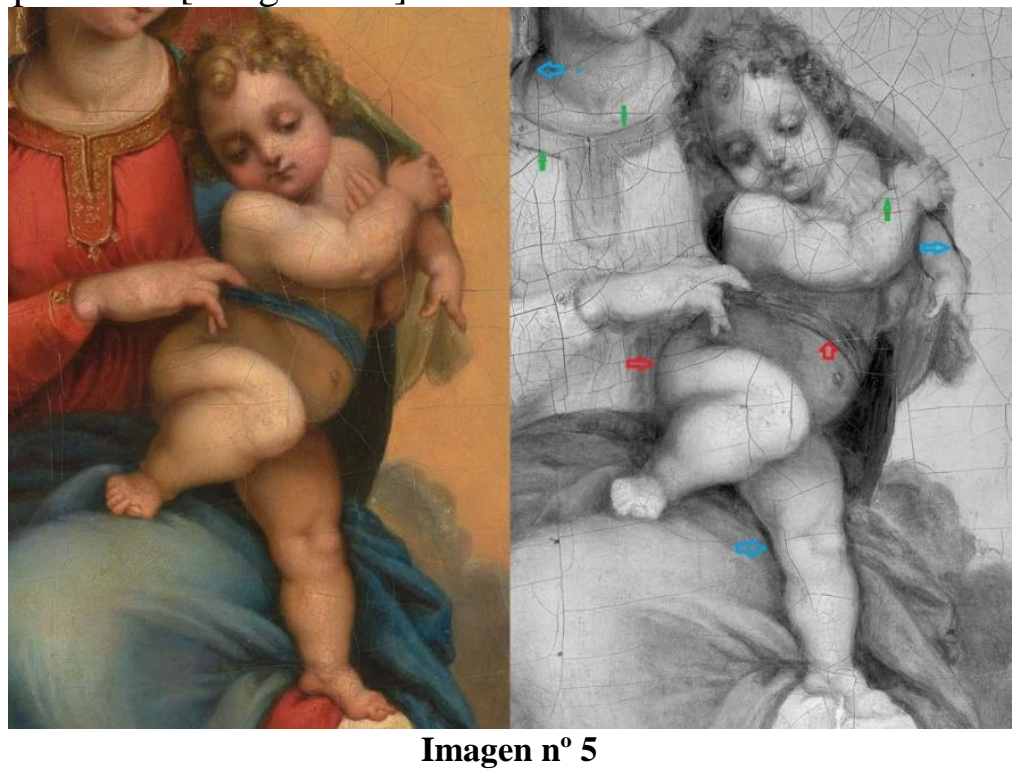

Además son perceptibles pequeños grupos de líneas paralelas en la figura de San Jerónimo, indicativas de una primera valoración del claroscuro en las fases iniciales de gestación de la pintura (Plazzotta, 2002: 133-135).

Completando este dibujo realizado con técnica seca, existen también otros perfiles subyacentes formalizados a pincel con un medio húmedo, ejecutados con pintura diluida con la finalidad de concretar los detalles y de potenciar la sensación de volumen en determinados motivos de la composición, como se observan en el perfil derecho del querubín, en su pierna y cabellos [Imagen $\left.n^{\circ} 6\right]$. 


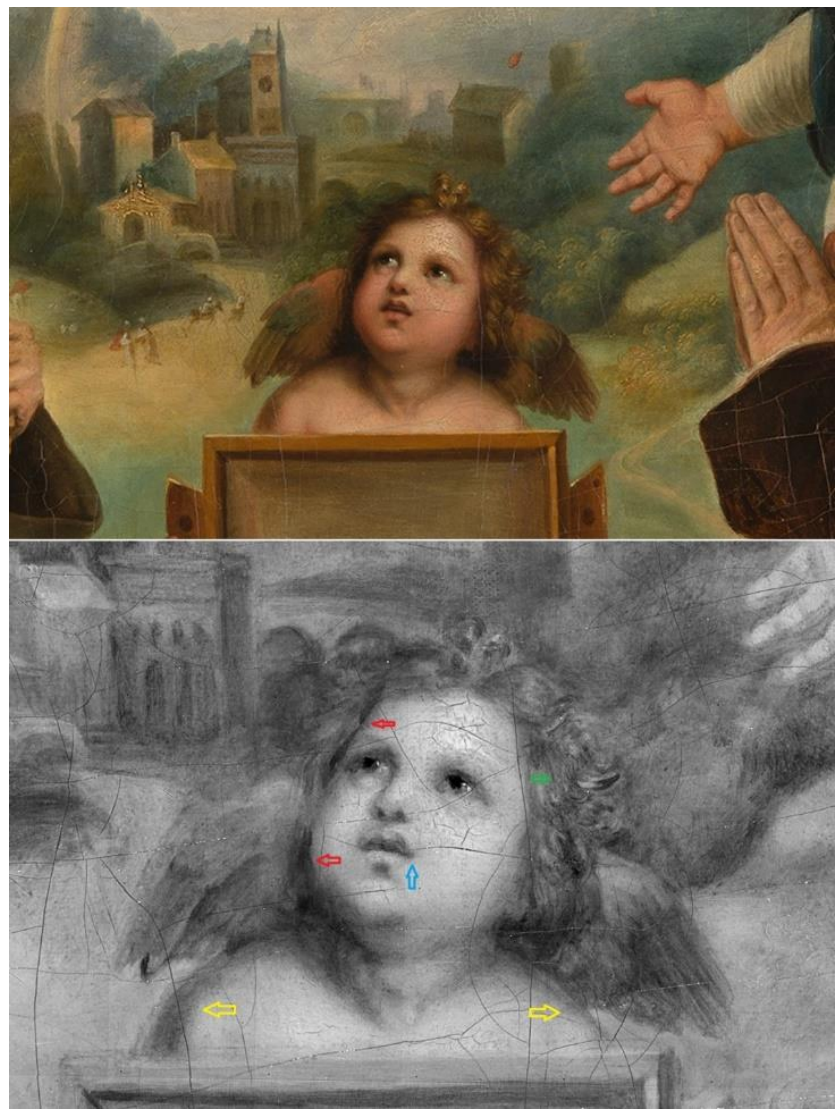

Imagen $n^{0} 6$

Este tipo de trazos a pincel aparecen también en las figuras de san Francisco, san Juan Bautista y Segismundo de Conti, siendo detectados asimismo en la mujer pía del Descendimiento Borghese, en el Éxtasis de santa Cecilia y en La Madonna del cordero (Falcucci, 2008: 16).

También los infrarrojos ponen en evidencia un silueteado más amplio constituido por una gruesa pincelada continua que rebordea los brazos, las manos y los pies de los personajes, destacando especialmente en los pies de la Madonna [Imagen $\mathrm{n}^{\mathrm{o}}$ 7].

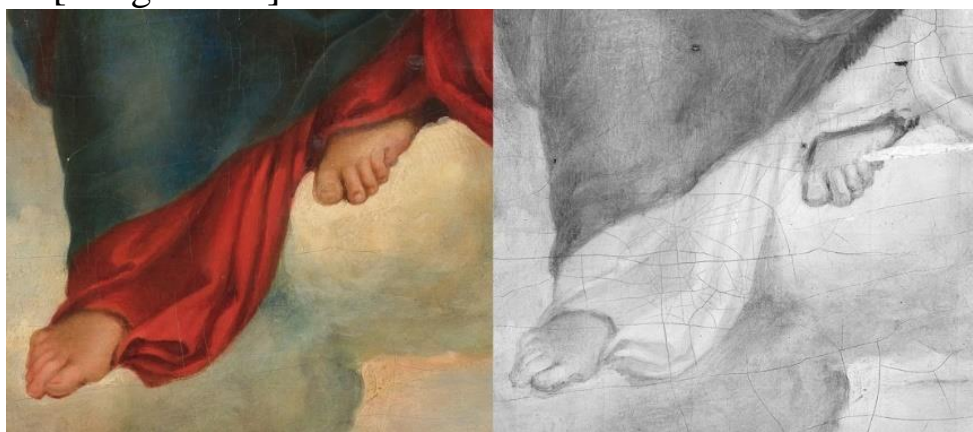

Imagen $n^{0} 7$ 
Esta manera de remarcar los contornos se ha detectado en la Fornarina, en el Retrato de un joven del Thyssen, en las reflectografías de los cartones para tapices de la Capilla Sixtina y en la Virgen del pez. (González, 2012: 324) y también en obras inacabadas como La Virgen del baldaquino.

El empleo de instrumentos de dibujo diferentes, desde la tiza al pincel, es bastante frecuente en las obras del pintor de Urbino (Falcucci, 2008: 16), permitiendo subrayar el acercamiento intelectual del artista a la creación de la imagen, con una elección consciente de cada uno de ellos para conseguir fines específicos (Bellucci y Frosinini, 2008: 92).

Esta combinación de diferentes técnicas, encontradas en el diseño interior de esta pintura, existe en otras obras de caballete pintadas por Rafael, con trazados subyacentes muy nítidos realizados con materiales distintos. Además, el dibujo subyacente de todas sus obras se circunscribe con exactitud a los contornos y a los principales detalles anatómicos de las figuras, a sus vestimentas y a los elementos arquitectónicos (González, 2012: 323), al igual que sucede en nuestra obra.

También se han observado algunas marcas de tiza negra o lápiz negro sobre las capas intermedias de la película pictórica realizadas durante el proceso de ejecución de la pintura, para modificar, definir y concretar algunos detalles, como ocurre en el vientre del niño Jesús [Imagen $\mathrm{n}^{\circ}$ 5], en el putto con la cartela [Imagen $\mathrm{n}^{\mathrm{o}} 8$ ], en los rostros de san Jerónimo y Segismundo de Conti y en el hábito de san Juan Bautista.

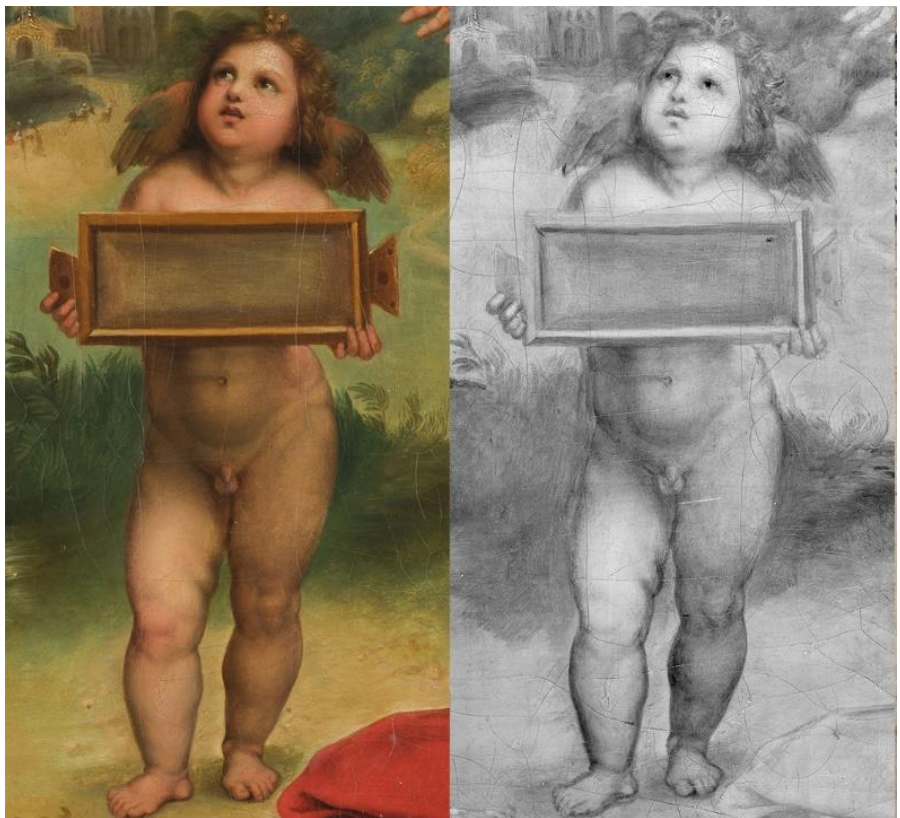

Imagen $\mathbf{n}^{\circ} 8$ 
Este proceder resulta indicativo del modo de trabajar de Rafael, que continúa elaborando y modificando sobre la propia pintura sus diseños previos en papel (Plazzotta, 2002: 135)

Este tipo de trazos, realizados sobre las capas de color cuando la ejecución pictórica estaba más o menos avanzada, han sido encontrados en otras obras de Rafael estudiadas con reflectografía infrarroja, como La Perla (González, 2012: 324).

Este complejo proceder en el dibujo subyacente pone de manifiesto la originalidad de la obra, como ocurre en el caso que nos ocupa, al revelar un trabajo muy complejo en las fases previas de la ejecución pictórica que queda oculto por los colores superficiales, por lo que difícilmente puede ser reproducido en una copia.

Los infrarrojos también permiten la visualización de las líneas originales que definen la expresión del rostro y de los ojos de la Virgen [Imagen $n^{\mathbf{o}}$ 9] (ocultos bajo un denso repinte perceptible visualmente), mostrando la mirada inclinada y las pestañas dibujadas con una fina raya de la que parten otras más cortas siguiendo la misma orientación de la mirada (Fischel, 2008: 47-51). Para Fischel la disposición de las pestañas con la misma orientación de la mirada constituye una característica propia de Rafael.

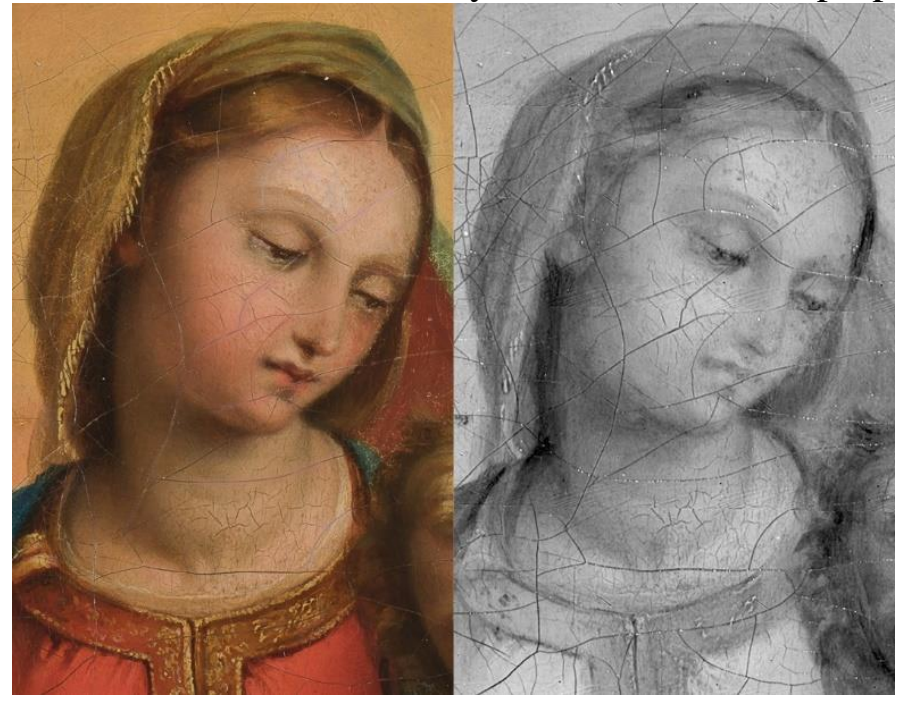

Imagen $\mathbf{n}^{0} 9$

Esta manera de pintar la expresión de los ojos aparece resuelta de la misma forma en otras muchas pinturas autógrafas de Rafael, como la Virgen del pez y La Sagrada Familia del cordero, entre otras. Los detalles del dibujo subyacente del rostro se perciben muy similares a los existentes en el dibujo conocido como Head of a Young Girl, del British Museum de Londres, realizado con punta de plata sobre tiza (inv. 1895-9-15-611). 
También esta técnica reflectográfica ha permitido observar las primeras fases de la gestación de la obra, materializada con pintura muy fluida, lo que permite la realización de rápidas pinceladas en distintas direcciones (González 2012: 327) y dinámicos brochazos hasta cubrir toda su superficie. Estas primeras pinceladas se perciben, a nivel interno, en el hábito de san Francisco y en las carnaciones masculinas, configuradas con empastes de albayalde sobre la base subyacente de una grisalla parda muy fluida, al igual que afirma González Mozo a propósito de otras obras de Rafael (2012: 336).

Este modelado subyacente coincide con el quehacer artístico del pintor de Urbino, mostrando una gran similitud con el planteamiento pictórico existente en Las Madonne del baldaquino y Esterházy, obras inacabadas que permiten la observación directa de estos recursos plásticos.

Estas grisallas de naturaleza aguada resultan apreciables igualmente en los reflectogramas de El Pasmo de Sicilia y La Perla (González, 2012: 327). Asimismo, en la Virgen de Foligno se han detectado estas capas subyacentes aplicadas en los primeros estadios de la ejecución pictórica, ofreciendo un aspecto gris-marronáceo (González, 2012: 348). Aquí encontramos otra concordancia técnica entre las dos pinturas, que no es la única.

También, los infrarrojos ponen de manifiesto las pequeñas rectificaciones introducidas por el pintor en el transcurso de la ejecución de la pintura, apreciables en todas las figuras presentes en nuestra composición, especialmente en el vientre y caderas del putto [Imagen $n^{\circ} 8$, derecha].

Todas estas modificaciones son propias del complejo proceso que supone la puesta en escena y el desarrollo de una composición original, y no de una copia, reforzando la autenticidad de esta pintura.

Pero además, el original de Rafael conservado en el Vaticano, de autoría indiscutible, también presenta estas pequeñas rectificaciones realizadas durante el transcurso de la ejecución de la pintura, como es el caso de las sutiles modificaciones existentes en la mano de san Juan Bautista y en los pies y en la silueta del manto de la Virgen, lo que no ha supuesto, sin embargo, un cuestionamiento de su autoría.

En relación con esta manera de trabajar, el número de pequeños cambios que han sido observados durante el examen técnico de sus pinturas en la National Gallery of Art de Washington, sugieren que gustaba experimentar con nuevas ideas sobre el dibujo ya plasmado en la tabla, introduciendo modificaciones a lo largo de todo el proceso creativo (Christensen, 1986: 54).

Asimismo con los infrarrojos hemos podido detectar la existencia de dos numeraciones subyacentes, situadas en los laterales superior (del 1 al 20, con 23 celdillas en horizontal) y derecho (del 1 al 30, con 32 celdillas en vertical), que además coinciden con pequeñas rayitas distribuidas de forma equidistante por todo el perímetro de la obra. Tanto unas como otras fueron 
ejecutadas sobre la pintura ya finalizada para traspasar esta composición a otra de mayor tamaño y ocultadas posteriormente con una fina capa de pintura. Pensamos que los dígitos se apuntaron previamente para indicar el número de divisiones a realizar, dibujándose posteriormente las rayitas para marcar con exactitud las medidas de las cuadrículas [Imagen $\mathrm{n}^{\circ} 10$ ].

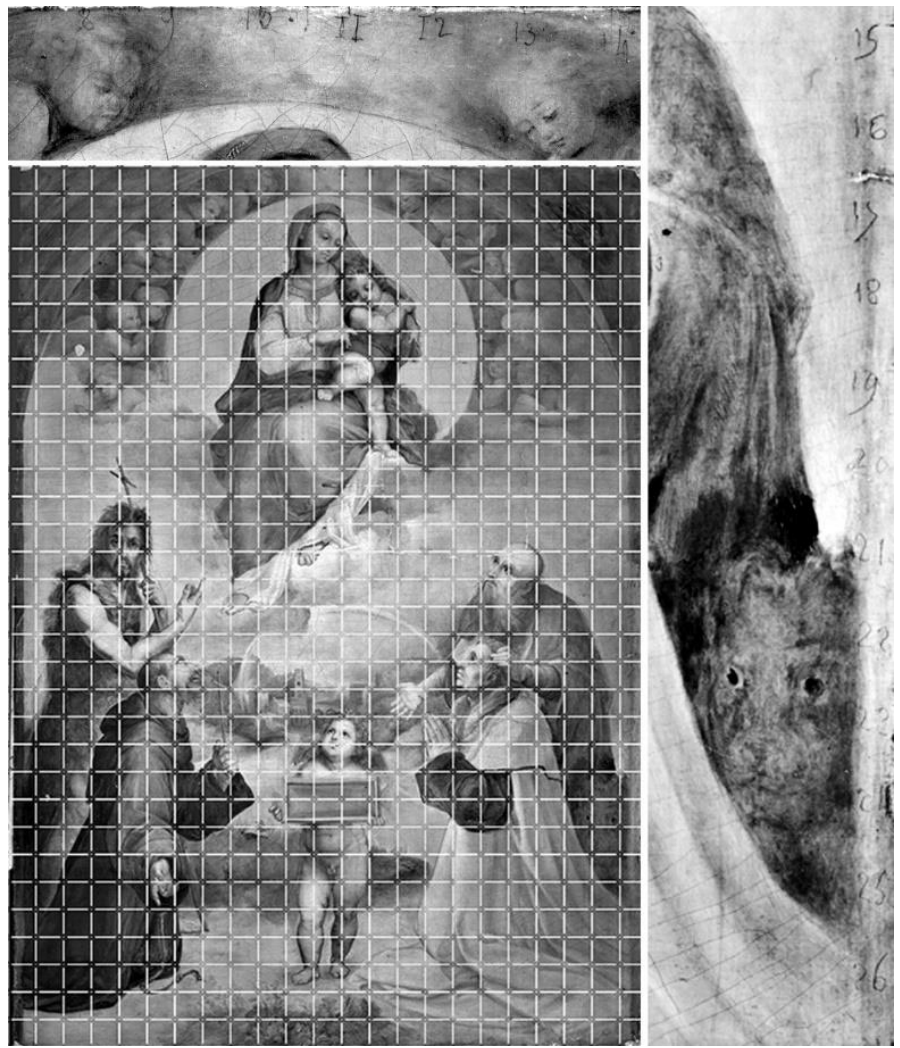

Imagen $n^{0} 10$

El planteamiento contrario no resulta verosímil, dado el tamaño de las casillas y el elevado $\mathrm{n}^{\mathbf{0}}$ de celdillas. Teniendo en cuenta la relación de tamaños entre las dos obras, en la Madonna de Foligno cada casilla tendría $10 \mathrm{~cm}$ aproximadamente y en La pequeña Madonna de Foligno miden $2,9 \mathrm{~cm}$, siendo imposible traspasar todos los grafismos incluidos en una casilla de $10 \mathrm{~cm}$ a otra de 2,9, ya que se perderían muchos detalles. Si las numeraciones y señales están realizadas sobre la pintura ya finalizada, no se puede afirmar que se hiciesen para copiar una gran composición reduciéndola de tamaño.

Partiendo de la existencia de estas numeraciones y señales ocultas, visualizadas con los infrarrojos, planteamos la hipótesis de que estas sirvieron para determinar un sistema de cuadriculado exento, que sirvió para la reproducción a gran escala de nuestra composición, como demuestra el 
pequeño tamaño de cada celdilla $(2,9 \mathrm{~cm})$ y el elevado número de casillas $(736$ cuadrículas) [Imagen $\mathrm{n}^{\mathrm{o}} 10$, centro].

De tratarse de una copia, dicho cuadriculado se hubiese dibujado internamente de forma completa con tiza negra o lápiz negro sobre la preparación blanca y debajo de las capas de color, y de esta forma se hubiera visualizado en la imagen capturada con reflectografía infrarroja, tal como ha sucedido en el Éxtasis de Santa Cecilia donde se han detectado vestigios del ajedrezado después de borrado (Bellucci y Frosinini 2008: 84).

Igualmente existen cuadrículas en La Sagrada Familia conocida como La Perla (Garrido 2006: 150-151-153), en los dibujos cuadriculados para el Descendimiento Borghese, en la Madonna Ansidei y en algunas de las pinturas murales de las estancias y logias vaticanas (Garrido 2006: 151; Plazzota 2002: 128; Joannides 1983: 59 y 123; Oberhuber 1999: 193-194).

El descubrimiento de estas rayitas y de las inscripciones numeradas, claras indicaciones subyacentes para un cuadriculado, posiblemente realizado con finas cuerdas sobre la composición finalizada, resulta determinante para afirmar que esta Pequeña Madonna de Foligno podría ser reconocida como el modelo para la gran pala de altar, valorándola por tanto como una obra original de Rafael con las prevenciones respecto de su intervención personal que ya hemos afirmado.

Es probable que la inclusión del retrato del comitente sea la razón por la que Rafael realizó este modelo con un alto nivel de terminación. Por otra parte, no resulta extraño en la producción del pintor de Urbino encontrar un trabajo precedente, bastante resuelto, para un encargo de gran importancia. Es el caso del prototipo, realizado a pincel e iluminado con toques en rayado paralelo de tiza blanca, para La Madonna del baldaquino (Chatsworth, colección del duque de Devonshire), en el que reproduce con tinta y otros materiales con técnica al seco los efectos de la pintura. Lo mismo se puede decir de La Perla de Módena, (Galleria Museo Estense, Módena), descubierta en 2010 y considerada obra autógrafa de Rafael por Mario Scalini (2010: 1131), estimándola un fragmento de una versión inicial de La Perla del Museo Nacional del Prado; de cualquier forma se trataría de un modelo bastante acabado. Sobre esta obra de Módena, al igual que en nuestro caso, se han efectuado análisis científicos que han permitido obtener un diagnóstico amplio y certero (Venerosi y Pelagotti, 2010: 33-47). La Perla de Módena reproduce el busto de la Virgen de La Perla exhibida en el Museo del Prado, aunque en la madrileña la disposición del busto de la Virgen se encuentra ligeramente girado con respecto a la disposición de la efigie de la de Módena

De La Madonna de Foligno de la Pinacoteca Vaticana solamente se han reproducido algunos detalles de los reflectogramas capturados con reflectografía infrarroja en el catálogo de la exposición de Dresde (Morresi y Santamaria 2011: 105-109) que no permiten deducir la existencia de algún 
sistema de trasposición del dibujo. Estos autores aluden únicamente al dibujo previo para las cabezas de los ángeles, que consideran realizado directamente sobre el fondo, omitiendo sin embargo cualquier referencia a otros tipos de grafismos subyacentes. Asimismo se encuentran otras sutiles referencias al dibujo preparatorio en el catálogo de la exposición Raffaello a Milano (2013) (Neselrath, 2013: 67; Santamaria y Morresi, 2013: 99), que ya hemos indicado en el estudio histórico artístico.

\section{Estructuración de la pintura e identificación de pigmentos}

El estudio de la estructuración estratigráfica y de la configuración de las distintas capas, a partir de la observación con microscopía óptica de las correspondientes secciones transversales, preparadas para tal fin, así como la localización, distribución, porcentaje e identificación de los pigmentos presentes en la pintura mediante SEM-EDX, se describe ampliamente en un artículo científico, en el que se explica y justifica de forma exhaustiva toda la información relativa a la secuencia de capas y a los pigmentos constituyentes de los distintos colores, reconocidos mediante estas técnicas instrumentales (Rodríguez-Simón 2015: 45-67), razón por la que completamos este apartado con una breve descripción de dicha investigación.

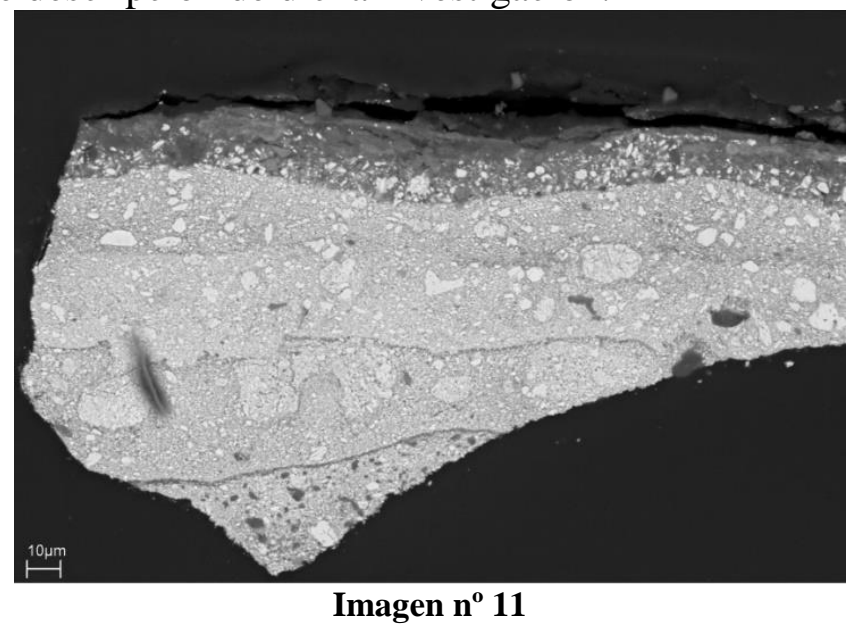

La estructuración interna de esta pintura está configurada por una gruesa preparación de blanco de plomo, compuesta por varias franjas, producto del proceso de transposición de tabla a lienzo realizado en Paris en el siglo XIX [Imagen $\mathrm{n}^{\circ} 11$ ]. Esta estructura responde a los sistemas de transposición de soporte efectuados durante el siglo XIX en Francia, siendo practicado sobre bastantes obras de Rafael, y coincidente con el llevado a cabo en El éxtasis de Santa Cecilia, (Rossi Maranesi, 1983: 264), concordando también con el procedimiento aplicado en el Museo del Louvre sobre La Madonna de Foligno 
para su transferencia a una nueva base de tela (Lacroix 1859; Rossi Maranesi, 1983: 264).

El cambio de soporte en nuestra pintura se realizó en Paris en el siglo XIX, como ponen de manifiesto los papeles antiguos adheridos sobre el reverso del bastidor durante el proceso de sustitución de su madera original.

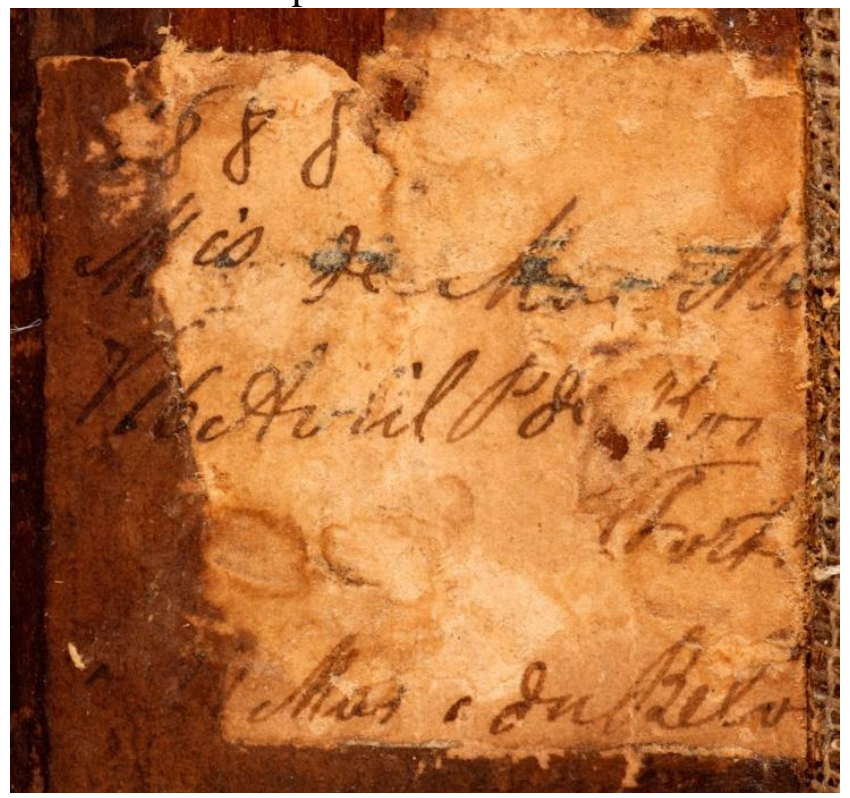

Imagen $\mathbf{n}^{0} 12$

Entre ellos existe un fragmento escrito en francés con tinta gálica, en el que se pueden apreciar las siguientes inscripciones: "1888", "V 16 Avril" "Mas", "Fort", y "Mas, du Belv" [Imagen n 12]. Y el trozo de un texto perteneciente a un catálogo de subastas de pinturas en el Hotel Drouot de Paris, impreso en 1872 [Imagen $n^{\circ} 13$ ].
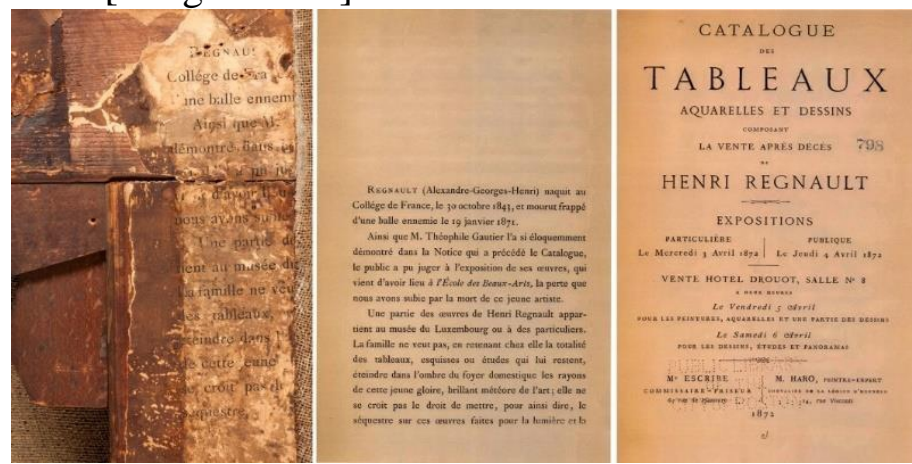

Imagen $n^{0} 13$

Datos que nos indican que dicha actuación se tuvo que realizar con posterioridad a la fecha de su impresión, siendo pegadas sus páginas para reforzar la adhesión de las nuevas telas a la parte trasera del bastidor de 
madera. Esto mismo ocurre en las pinturas de Rafael en el Museo del Prado que fueron trasladadas de soporte, cuyos bordes fueron sellados con papel (Garrido 1985: 110).

Sobre este conjunto de capas de blanco de plomo existe un cuarto estrato de cerusita, localizado inmediatamente debajo de las franjas de color, que podría tratarse de la imprimación blanca original (Rossi Maranesi 1990:125-134; Mottin 2012: 357), que, afortunadamente, se conservó en el transcurso de la transferencia de tabla a lienzo, como ocurrió en la Sagrada Familia de Francisco I (Mottin, Ravaud, Bastian y Eveno 2012: 351). En ambos casos el dibujo subyacente no se perdió en dicho proceso.

Las secciones transversales ponen de manifiesto que la estructuración interna de esta pintura se encuentra configurada por la superposición de varias capas luminosas en las áreas de luz, mientras que en las zonas de sombra muestran una organización diferente, visualizándose más claras en los niveles internos y más oscuras en los estratos exteriores, en los que se utilizan veladuras superficiales para ensombrecer. Los colores están conseguidos mediante la incorporación sucesiva de capas y no por mezcla, recurso que es considerado como un método de trabajo propio de Rafael (González 2012: 331) [Imagen $\left.n^{\circ} 14\right]$.

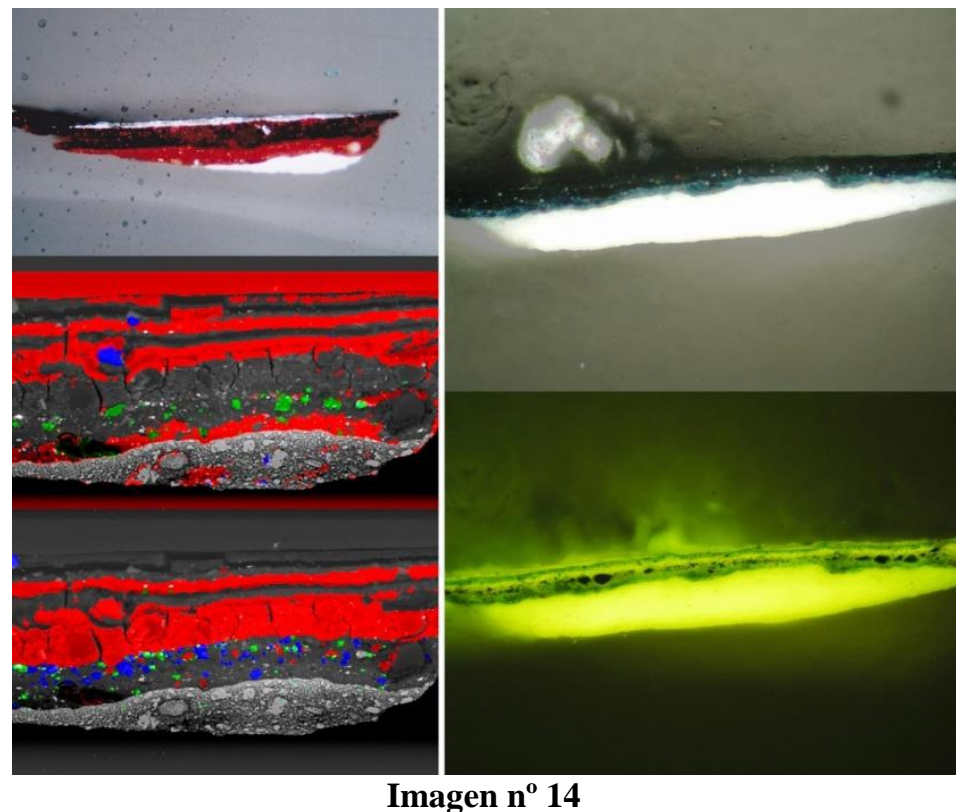

La túnica roja de la Virgen y la dogalina de Segismundo de Conti [Imagen $\mathrm{n}^{\mathbf{0}}$ 14, izquierda] aparecen elaboradas con múltiples estratos superpuestos de bermellón de mercurio en las primeras capas, y sobre ellas laca roja en ligeros toques de glacis para dar transparencia a los colores, al 
igual que ocurre en los rojos existentes en las pinturas de Rafael del Museo del Prado (Garrido 1985: 127). Además de bermellón y laca roja, en nuestro caso se han caracterizado también óxidos de hierro rojos. Las sombras se muestran reforzadas con pinceladas fluidas de laca roja y bermellón mezclados con negro, al igual que afirma Ana González Mozo en el catálogo de la exposición El último Rafael, a propósito de la producción romana de Rafael (González, 2012: 332). También se encuentran de forma minoritaria, amarillo de plomo y estaño y lapislázuli, para matizar la tonalidad rojiza; y calcita para dar cuerpo y transparencia a los colores [Imagen $n^{\circ} 14$ izquierda, central e inferior].

Esta estructuración de capas superpuestas presentes en las estratigrafías de los colores rojos existe también en la Madonna di Foligno, comprobándose que la sección transversal del manto de la Virgen del Vaticano tiene una configuración muy similar a la que muestra la dogalina de Conti en nuestra pintura, revelando en ambos casos la sucesión estratigráfica típica del proceder artístico de Rafael, tal como afirman Santamaría y Morresi en la investigación científica realizada sobre la versión vaticana a propósito de la exposición Raffaello a Milano. La Madonna di Foligno (Santamaria y Morresi, 2013: 95).

Los colores azules muestran una configuración similar a la encontrada en las vestiduras rojizas, ordenándose en varias capas que aumentan en número desde las áreas iluminadas a las zonas en sombra [Imagen $n^{\circ} 14$ derecha]. En estos se han identificado lapislázuli, blanco de plomo y azul cobalto, con la adición de otros pigmentos con presencia minoritaria como, cinabrio y óxidos de hierro rojos, malaquita y negro de huesos, añadidos con la finalidad de modular la intensidad de los añiles.

Asimismo, en los estratos más internos hemos detectado, mezclada con los azules, laca roja en gran proporción, tal como sucede en las obras autógrafas de Rafael del Museo del Prado (Garrido 1985: 127), produciendo un fondo de tonalidad rosada relacionado con la base cromática de laca roja debajo del azul de cielos y paños, tal como apuntan Riitano y Seccaroni (2008: 98) a propósito del Éxtasis de santa Cecilia y de las Madonne del baldaquino, de Foligno, de Francisco I, de la diadema y de los candelabros. También esta laca roja aparece incorporada directamente en los azules, con la finalidad de modificarlos sutilmente, aportando profundidad y riqueza a los colores oscuros de los ropajes sin que pierdan transparencia, como apunta Ana González Mozo en El último Rafael (González 2012: 348, nota 47), lo que también sucede en nuestro caso.

El azul cobalto podría tratarse de un pigmento anacrónico en relación a la época de la pintura. Por esta razón planteamos la hipótesis de que su incorporación en la pintura pudiera haberse realizado posiblemente en la manipulación de la obra durante su trasposición de tabla a lienzo, operación realizada en el siglo XIX. 
También podría considerarse como un color utilizado por el propio Rafael, como ocurre en el caso del amarillo de Nápoles, sobre el que una investigación ha demostrado su uso por el pintor de Urbino, que lo utilizó en la Logia de Psique de la Villa Farnesina en Roma (Sandalinas y Ruiz-Moreno 2004: 41-52).

Recientemente y con posterioridad a nuestra investigación, un estudio realizado con Difracción de Rayos X para la identificación de los pigmentos presentes en La pequeña Madonna de Foligno afirma, en sus resultados y conclusiones, que el azul de cobalto sintético, pigmento anacrónico conocido como Azul de Thenard, no ha sido encontrado en ninguno de los puntos analizados (Martín-Ramos et al. 2017: 352), por lo que quizá el azul de cobalto se trate realmente de azul de esmalte propio de la época.

En nuestro caso, la caracterización del azul de cobalto se ha planteado a partir del alto pico de aluminio que aparece en todos los espectros adquiridos con microanálisis por microcroscopía electrónica de barrido, aunque posiblemente la elevada altura del pico de aluminio nos haya podido llevar a una confusión en la identificación del pigmento. Por lo que este color azul pudiera tratarse realmente del conocido "esmalte", ya que, junto a los picos de cobalto, aluminio y silicio, en algunos espectros aparecen también calcio y sodio, y en otros calcio, sodio y potasio, que podrían caracterizar al azul de esmalte, según la bibliografía consultada.

Igualmente, la estructuración estratigráfica de las carnaciones responde a una superposición de estratos, con blanco de plomo como masa matriz y otros pigmentos rojizos como cinabrio, óxidos de hierro rojos y laca roja; también están presentes cuarzo y calcita y otros tintes minoritarios, como lapislázuli, azul cobalto y amarillo de plomo y estaño, añadidos para enfriar el tono de las carnaciones. Es interesante destacar en estas la presencia, en pequeñas cantidades, de amarillo de plomo y estaño, en unión con el blanco de plomo y también la de bermellón de mercurio como anota Carmen Garrido en el catálogo de la exposición Rafael en España (Garrido 1985: 128). La configuración del modelado de las carnaciones masculinas se percibe de manera semejante a la descrita en La Madonna de Foligno por Ana González Mozo (González 2012: 348).

Las tonalidades verdosas resultan configuradas mediante un estrato de color verde azulado claro, coincidente con la tonalidad de las zonas adyacentes del suelo, sobre el que se extienden varias veladuras oscuras de verde intenso, superpuestas para graduar los diferentes matices presentes en las distintas especies botánicas; estructura detectada en otras pinturas de Rafael (Mottin 2012: 354), organizándose también en diferentes capas para graduar sus tonalidades (Garrido 1985: 128). En su elaboración intervienen mayoritariamente laca verde, blanco de plomo, óxidos de hierro amarillos y negro de huesos y también otros pigmentos minoritarios como laca roja, 
lapislázuli y azul cobalto, añadidos para armonizar los matices verdosos de las plantas.

Al igual que ocurre en el caso de la dogalina rojiza de Conti, en la estratigrafía de la vegetación de la zona inferior de la pintura La pequeña Madonna de Foligno se evidencia una sucesión de capas que aparecen dispuestas del mismo modo en la sección transversal correspondiente de la Madonna di Foligno de la Pinacoteca Vaticana (Santamaría y Morresi, 2013: 93), encontrando una gran similitud entre ellas. En ambos casos, estas coincidencias establecen una relación muy directa entre La pequeña Madonna de Foligno y La Madonna de Foligno de la Pinacoteca Vaticana.

Igualmente, los grises y verdosos del hábito de san Francisco se distribuyen en varios estratos, respondiendo también su estructura al proceder creativo de Rafael (González 2012: 331). Están constituidos por la mezcla de los siguientes pigmentos: blanco de plomo, óxidos de hierro amarillos y negros, malaquita, laca roja, cuarzo y calcita.

Las tonalidades anaranjadas responden estratigráficamente a una superposición de capas finas que van aumentando de grosor hacia la superficie, a la vez que aclaran su tonalidad. En su composición participan mayoritariamente blanco de plomo, óxidos de hierro amarillos y laca roja y, minoritariamente, negro de vid, bermellón de mercurio y calcita. En las amarillentas del suelo también predominan los óxidos de hierro amarillos con pequeñas cantidades de negro de huesos.

En las estratigrafías de las montañas azules, carnaciones del putto reggitarga y de san Juan Bautista, hábito de san Francisco, aureola solar anaranjada y suelo del paisaje, se percibe con total nitidez un fino estrato interior, de naturaleza orgánica, que relacionamos con la aguada inicial a modo de grisalla aplicada por Rafael en las primeras fases de la ejecución pictórica, con la finalidad de estructurar las formas mediante dinámicos brochazos con los que define el modelado de las figuras valorando las luces, las sombras y los medios tonos, como anota Ana González Mozo (González 2012: 327).

Estas manchas internas destacan por su delgadez y por la fluidez de la pasta pictórica debido a la predominancia del aglutinante, percibiéndose como un fino estrato amarillento en las secciones transversales de La pequeña Madonna de Foligno, con una fluorescencia especial en las microfotografías con iluminación ultravioleta. Observándose, de igual manera y con las mismas características, en algunas estratigrafías de la Madonna de Foligno Vaticana (Santamaría y Morresi, 2013: 95).

La complejidad detectada en las secciones transversales estudiadas, materializada por una parte en la superposición de estratos internos, producto de la incorporación sucesiva de capas y, por otra, en la adición en pequeñas proporciones de distintos pigmentos juntos al color mayoritario, con la 
finalidad de modificarlo sutilmente, responden al proceder creativo de Rafael y pone de manifiesto la originalidad de esta pintura, ya que en una copia resulta imposible imitar la compleja estructuración interna de una obra.

\section{Análisis de Aglutinantes}

El análisis de aglutinantes (Rodríguez-Simón 2015: 22-23) se ha llevado a cabo mediante cromatografía de gases-espectrometría de masas, a partir de dos micromuestras extraídas de la superficie de la pintura, obteniéndose unos cromatogramas con los picos característicos de los ácidos azelaico, palmítico y esteárico que nos indican que los pigmentos han sido aglutinados con aceite secante.

Para la caracterización del tipo de aceite secante se ha procedido estableciendo la correlación existente entre la composición en ácidos grasos presentes en las muestras envejecidas, empleando un método analítico basado en hallar el cociente entre las cantidades relativas de ácido palmítico y ácido esteárico obtenidas tras el análisis cromatográfico. Este cociente C16/C18 $[\mathrm{P} / \mathrm{S}]$, por tratarse de ácidos grasos saturados no reactivos, permanece invariable durante el secado, resultando característico para cada tipo de aceite, siendo en gran medida independiente del pigmento que esté presente (Mills, J.S. and White: 1987).

Por otra parte el ácido azelaico, principal producto de degradación de los aceites secantes, también se utiliza para la caracterización de este tipo de substancias, en concreto la relación ácido azelaico/ácido palmítico (2C9/C16) $[\mathrm{A} / \mathrm{P}]$ que es característica de cada aceite. No obstante, este valor va a depender de factores tales como mezclas de aglutinantes, presencia de pigmentos (Gimeno-Adelantado et al.: 2001) y envejecimiento de la muestra.

Los resultados obtenidos arrojan los siguientes valores:

Muestra $\mathrm{n}^{\circ} 1$ (Verde especies vegetales): $\mathrm{A} / \mathrm{P}=0,25$ y $\mathrm{P} / \mathrm{S}=0,67$

Muestra $\mathrm{n}^{\mathrm{o}} 2$ (Arco marrón): $\mathrm{A} / \mathrm{P}=0,13$ y $\mathrm{P} / \mathrm{S}=0,79$

Atendiendo a la bibliografía consultada (Gimeno-Adelantado et al.: 2001) los valores obtenidos mediante el análisis cromatográfico nos sugieren la presencia de aceite de linaza, teniendo en cuenta la posible influencia que sobre los valores característicos de este aceite estarían ejerciendo las gruesas capas de blanco de plomo presentes en las muestras. Aceite secante que determina la técnica pictórica al óleo.

Como ya se ha explicado en la descripción de las estratigrafías, estas capas de blanco de plomo fueron incorporadas en el proceso de transposición de tabla a lienzo realizado sobre la obra. Además, en las capas originales de imprimación y en los estratos pictóricos, el blanco de plomo se encuentra con una alta representación al conformar la imprimación blanca oleosa y aparecer mezclado con los distintos pigmentos para la consecución de los colores definitivos. 


\section{La Firma}

El cuadro de La pequeña Madonna de Foligno se encuentra firmado en la bocamanga de la túnica roja de la Virgen mediante un anagrama con las letras "RU” ó "RV" [Imagen n' 15, superior], de manera semejante a como Rafael lo hizo en la Madonna de Foligno, de la Pinacoteca Vaticana, donde se observa un rúbrica similar formando parte de la decoración dorada de la bocamanga de su túnica.

Además, en la muñeca de la mano derecha de la Virgen se visualiza una "R" junto a unos grafismos que no pueden identificarse [Imagen 15, superior]. Sin embargo, la observación de la superficie pictórica mediante una cámara fotográfica con lentes de aproximación ha permitido visualizar estos mismos grafismos, detectándose que están realizados de forma incisa con un fino instrumento cuando la pintura se encontraba casi seca. En estos pueden apreciarse parte de unas letras reproduciendo posiblemente el inicio del nombre de Raffaello: “RAF...” y debajo de ellas el guarismo “1507”. [Imagen $\mathrm{n}^{\mathrm{o}} 15$, inferior]

El hecho de que estos grafismos hayan sido realizados sobre el óleo cuando se encontraba en estado mordiente demuestra su autenticidad, ya que de haber sido ejecutados sobre la pintura seca no mostrarían los surcos limpios a nivel microscópico, sino de forma accidentada como consecuencia de las micropartículas que saltarían al pasar el punzón sobre ella.

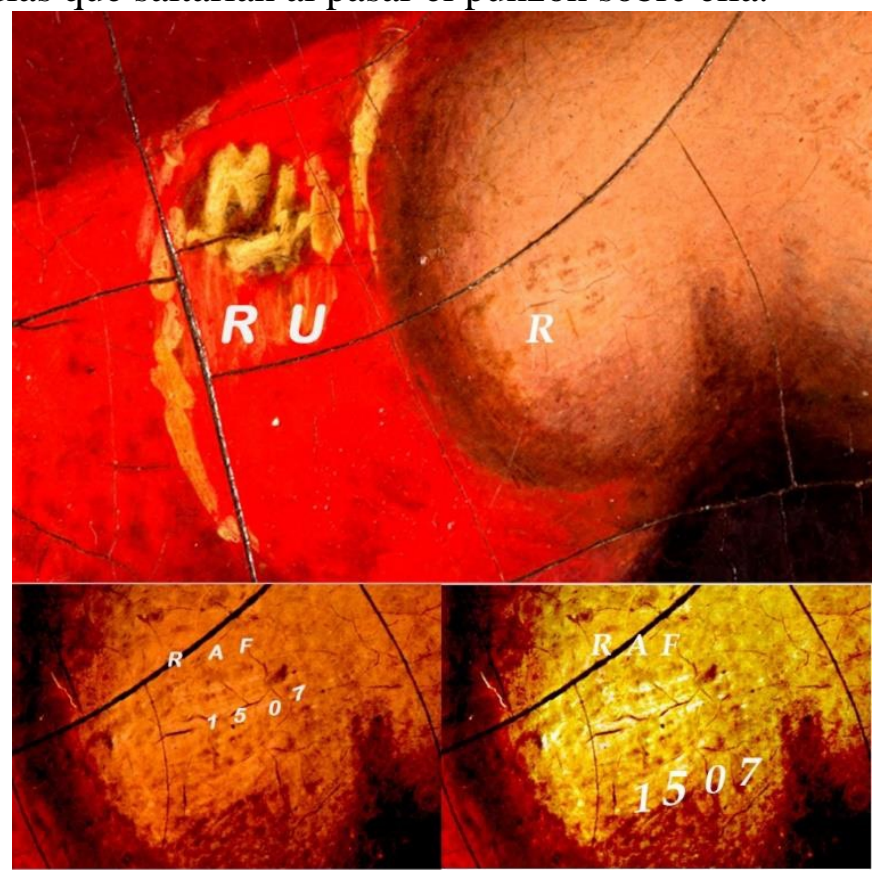

Imagen $n^{0} 15$ 


\section{Conclusiones}

Teniendo en cuenta los documentos adquiridos y los estudios comparativos sobre aspectos estéticos y técnicos con otras pinturas autógrafas del pintor de Urbino, planteamos que La Pequeña Madonna de Foligno es una obra original de Rafael Sanzio, Y demostramos la importante aportación que los métodos científicos pueden suponer en la autentificación, atribución y originalidad de las obras de arte.

A partir de la interpretación de los resultados se puede concluir que esta pintura fue creada sobre un soporte de madera y posteriormente traspasada a lienzo en Francia, en la segunda mitad del siglo XIX; cronología confirmada por los fragmentos de papel pegados en el reverso del bastidor, que evidencia la imposibilidad de que se trate de una copia realizada en esta misma centuria.

Los documentos radiográficos no permiten una lectura clara de las imágenes producidas por los pigmentos radiopacos presentes en los distintos motivos de la composición, lo que impide poder determinar el alcance de las intervenciones restauradoras realizadas en Francia en el siglo XIX.

Con reflectografía infrarroja se ha detectado una combinación de técnicas distintas en el dibujo subyacente, oculto bajo las capas de color. Por una parte, trazos finos ajustado a los contornos y también sombreados de líneas paralelas, todos ellos realizados con piedra negra o lápiz negro. De otra, perfiles formalizados a pincel con un medio húmedo. Estos distintos procedimientos que han sido detectados también en obras autógrafas de Rafael.

Asimismo los infrarrojos han puesto en evidencia sendas numeraciones en los laterales superior $\mathrm{y}$ derecho y pequeñas rayitas equidistantes distribuidas por todo el perímetro de la obra, lo que induce a plantear la posibilidad de que la Pequeña Madonna de Foligno sea el modelo del gran cuadro del Vaticano.

Se han identificado los pigmentos constituyentes utilizados por el pintor en esta obra, caracterizados como materiales artísticos propios del siglo XVI, lo que reafirma nuestra convicción de que se trata de una obra de la época y no de una copia del siglo XIX: blanco de plomo, laca orgánica roja, bermellón, óxidos de hierro rojos, amarillos y negros, lapislázuli, azul cobalto (o de esmalte), amarillo de plomo y estaño, negro de huesos, malaquita, tierra verde y laca verde, cuarzo y calcita.

El análisis cromatográfico sugiere la presencia del aceite de linaza como aglutinante de los pigmentos, lo que determina que la técnica pictórica es el óleo.

Cabe destacar como recursos pictóricos utilizados por Rafael en otras obras autógrafas el uso de pigmentos minoritarios para matizar los colores, como la incorporación del lapislázuli y de amarillo de plomo y estaño en los rojizos; bermellón, óxidos de hierro rojos y laca roja en los azules y 
lapislázuli y amarillo de plomo y estaño en las carnaciones; pigmentos que han sido detectados en La Pequeña Madonna de Foligno.

La complejidad detectada en las secciones transversales estudiadas (materializada en la superposición de estratos internos, producto de la incorporación sucesiva de capas, y en la adición en pequeñas proporciones de distintos pigmentos junto al color mayoritario, con la finalidad de modificarlo sutilmente) responde al proceder creativo de Rafael y pone de manifiesto la originalidad de la pintura, ya que en una copia resulta imposible imitar la compleja estructuración interna de una obra.

Pensamos que la existencia de pequeñas diferencias entre nuestra obra y La Madonna de Foligno, son indicativas de la originalidad de la pintura objeto de nuestro estudio

Por otra parte, podemos establecer una correspondencia directa entre las dos composiciones para apoyar nuestra teoría de la originalidad de esta pintura, con la constatación en ambas de pequeñas rectificaciones realizadas durante el transcurso de su ejecución, como es el caso de las sutiles modificaciones existentes en la mano de San Juan Bautista y en los pies y silueta del manto de La Virgen.

Y también por la gran similitud existente, a nivel interno, en las secciones transversales del manto rojo de la Virgen en La Madonna de Foligno de la Pinacoteca Vaticana y la estratigrafía de la dogalina de Segismundo de Conti en La pequeña Madonna de Foligno.

Asimismo, en la estratigrafía de la vegetación de la zona inferior de la pintura de La pequeña Madonna de Foligno se evidencia una sucesión de capas que aparecen dispuestas del mismo modo en la sección transversal correspondiente de la Madonna di Foligno de la Pinacoteca Vaticana (Santamaría y Morresi, 2013: 93), existiendo una gran similitud entre ellas.

En ambos casos, estas coincidencias estratigráficas establecen una relación muy directa entre La pequeña Madonna de Foligno y La Madonna de Foligno de la Pinacoteca Vaticana.

\section{References:}

1. Alberti, L. B. (1999). De la pintura y otros escritos sobre arte (ed. de Rocío de la Villa), Madrid: Tecnos.

2. Bellucci, R.; Frosinini, C. (2008). "Nuove indagini riflettografiche su Raffaello. Riflessioni per la pianificazione, l'elaborazione e la tecnica dell'underdrawing". In Raffaello: la rivelazione del colore. Il restauro della Madonna del Cardellino della Galleria degli Uffizi (cura di Marco Ciatti, Cecilia Frosinini, Antonio Natali, Patrizia Riitano), Firenze: Edifir.

3. Bellucci, R.; Frosinini, C. (2007)"Design, Elaboration and Technique in Raphael's Underdrawing", in Ashok Roy and Marika Spring (eds.), 
Raphael's Painting Technique: Working Practices before Rome, Firenze: Nardini, Kermesquaderni.

4. Bonis, V. M. de (2013). "Alta virtute e bel sembiante adorno. Estetica petrarchesca, sprezzatura e classica armonía, fra Pietro Bembo e Baldassar Castiglione, nell'universo ideale di Raffaello Sanzio”. En Valeria Merlini y Daniela Storti, Raffaello a Milano. La Madonna de Foligno, Milano: 24 ORE Cultura.

5. Coliva, A. (2006). "Raffaello da Firenze a Roma". En Coliva, Anna (ed.). Raffaello da Firenze a Roma, Milano: Skira.

6. Chapman, H. and Faietti, M (2010). Fra Angelico to Leonardo, Italian Renaissance, Drawings, London: The British Museum Press.

7. Christensen, C. (1986). "Examination and Treatment of Paintings by Raphael at the National Gallery of Art". In Beck, James (ed.), Raphael Before Rome, Washington: National Gallery of Art.

8. Del Egido, M., Juanes, D. (2010), La Ciencia y el Arte II. Ciencias experimentales y conservación del Patrimonio Histórico. Madrid: Ministerio de Cultura.

9. Falcucci, C. (2008). "La tecnica esecutiva delineata attraverso le indagini diagnostiche", en Raffaello, La Madonna dell'Agnello, Indagini diagnostiche, Foligno: Centro Gráfico Editoriale.

10. Ferino Pagden, S. y Zancan, A. (1992). Rafael. Catálogo completo de pinturas. Madrid: Akal.

11. Fischel, O. (2008). "Madonna dell'Agnello" (Perizia), en Falcucci, Claudio. Raffaello, La Madonna dell'Agnello, Indagini diagnostiche, Foligno: Centro Gráfico Editoriale.

12. Garrido Pérez, C. (1985). "Consideraciones técnicas sobre las pinturas de Rafael del Museo del Prado", en Rafael en España, cat. exp. Manuela Mena Marquez (ed.), Madrid: Museo Nacional del Prado.

13. Garrido Pérez, C. (2006). "El trazo oculto. Dibujos subyacentes en las tablas del Museo del Prado", en Finaldi, G. y Garrido, C. (eds). El trazo oculto. Dibujos subyacentes en pinturas de los siglos XV y XVI. Madrid: Museo Nacional del Prado.

14. Giorello, G. (2013). “L'armonia dell'invisibile”. En Valeria Merlini y Daniela Storti, Raffaello a Milano. La Madonna de Foligno, Milano: 24 ORE Cultura.

15. Gimeno Adelantado, J.V. et al. (2001). "Identification of lipid binders in paintings by gas chromatography. Influence of the pigments". Journal of Chromatography A, (pp. 385-390), 922 (2001).

16. González Mozo, A. y Alonso, R. (2011). "Reflexión ante la restauración del Pasmo de Sicilia, de Rafael", Boletín del Museo del Prado, 47 (pp.104-119). 
17. González Mozo, A. (2012). "La técnica pictórica de Rafael en Roma", En Henry, Tom y Joannides, Paul (eds), El último Rafael, cat. exp., Madrid: Museo Nacional del Prado.

18. Ibáñez Barberán, G. coord. (2010). El nacimiento de una pintura: De lo visible a lo invisible. Valencia: Generalitat Valenciana.

19. Jones, R.; Penny, N. (1983). Raphael, New Haven / London: Yale University Press.

20. Lacroix, P. (1859). "Rapport a L'Institut National sur la Restauration du Tableau de Raphaël connu sous Le nom de La Vierge de Foligno", Revue Universalle des Arts, Paris.

21. Martín-Ramos, J.D., Zafra-Gómez, A., Vilchez, J.L. (2017). "Nondestructive pigment characterization in the painting Little Madonna of Foligno by X-ray Powder Diffraction. Microchemical Journal 134, (pp. 343-353).

22. Matteini, M., Moles, A., (2001) Ciencia y Restauración. Método de Investigación. Sevilla, Junta de Andalucía: Nerea

23. Meyer Zur Capellen, J. (2006). "Raffaello da Perugia, Firenze e Roma: la committenza". En Coliva, Anna (ed.). Raffaello da Firenze a Roma, Milano: Skira.

24. Milss, J.S. and White (1987). The organic chemistry of museum objects. Reino Unido: Ed. Butterworth.

25. Mogford, H. (1851), Hand-Book for the Preservation of Pictures. Containing Practical Instructions for Cleaning, Lining, Repairing, and Restoring Oil Paintings, London: Third Edition.

26. Morresi,F.; Santamaria, U. (2011). "Maltechnologische untersuchungen zu Raffaels Madonna von Foligno. In Himmlischer Glanz. Raffael, Dürer und Grünewald malen die Madonna (Herausgegeben von Andreas Henning und Arnold Nesselrath), Dresden: Staatliche Kunstsammlungen Dresden.

27. Mottin, B.; Ravaud, E.; Bastian, G. y Eveno, M. (2012). "En torno a Rafael en Roma: Estudio técnico de los cuadros del Musée du Louvre", en Tom Henry y Paul Joannides, El Último Rafael, Madrid: Museo Nacional del Prado.

28. Messelrath, A (2013). "La Madonna di Foligno”. En Valeria Merlini y Daniela Storti, Raffaello a Milano. La Madonna de Foligno, Milano: 24 ORE Cultura.

29. Nesselrath, A (2013). "Sigismondo de' Conti". En Valeria Merlini y Daniela Storti, Raffaello a Milano. La Madonna de Foligno, Milano: 24 ORE Cultura.

30. Pinna, D.; Galeotti, M.; Mazzeo, R. (2009). Scientific Examination for the Investigation of Paintings. A Handbook for Conservator-restorers. Firenze: Centro Di della Edifimi srl. 
31. Plazzotta, C. (2002). "Raphael (Raffaello Santi), The Madonna and Child with the Infant Baptist (The Garvagh Madonna). In Bomford, David (ed.), Art in the Making. Underdrawings in Renaissance paintings, London: National Gallery Company.

32. Prous, S. (2008), La Ciencia y el Arte. Ciencias experimentales y conservación del Patrimonio Histórico, Madrid: Ministerio de Cultura.

33. Riitano, P.; Seccaroni, C. (2008). "Attorno all'imprimitura" en Raffaello: la rivelazione del colore. Il restauro della Madonna del Cardellino della Galleria degli Uffizi, Marco Ciati, Cecilia Frosinini, Antonio Natali, Patrizia Riitano (eds.), Florencia: Edifir.

34. Rodríguez-Simón, L.R. (2015). "El proceso creativo y la estructuración estratigráfica como señas de identidad y autenticidad. La pequeña Madonna di Foligno de Rafael, como caso de estudio", PH INVESTIGACIÓN, 5 (pp. 45-67).

35. Rossi Manaresi, R. (1990). "A Technical Examination of Raphael's Santa Cecilia with Reference to the Transfiguration and the Madonna di Foligno", in John Shearman and Marcia B. Hall, (eds.), The Princeton Raphael Symposium: Science in the Service of Art History, Princeton: Princeton University Press

36. Rossi Manaresi, R. (1983). "Contributi analitici allo studio della Santa Cecilia di Rafaello" en Indagini per un dipinto La Santa Cecilia di Raffaello, Bologna: Alfa.

37. Sandalinas, C. y Ruíz-Moreno, S. (2004) "Lead-Tin-Antimony Yellow. Historial Manufacture, Molecular Characterization and Identification in Seventeenth-Century Italian Paintings, Studies in Conservation, 49 (pp. 41-52).

38. Santamaria, U. y Morresi, F. (2013). "Indagini scientifiche”. En Valeria Merlini y Daniela Storti, Raffaello a Milano. La Madonna de Foligno, Milano: 24 ORE Cultura.

39. Scalini, M. (2010). La Perla di Modena. Un Raffaello ritrovato. Milano: Silvana Editoriale.

40. Talvacchia, B. (2007), Rafael, Barcelona: Phaidon Press.

41. Vasari, G. (1992). Le vite dei più celebri pittori, scultori e architetti. Milano: Fratelli Melita Editori.

42. Venerosi y Pelagotti (2010) 'Un'attribuzione possibile: un percorso in tre", en La Perla di Modena un Raffaello ritrovato, Milano: Silvana Editoriale, 2010.

43. Violini, P. (2013). "Movimentazioni, trasporti e restauri di un caplavoro”. En Valeria Merlini y Daniela Storti, Raffaello a Milano. La Madonna de Foligno, Milano: 24 ORE Cultura. 